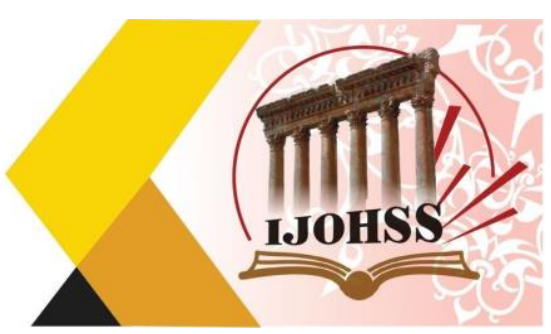

\title{
توظيف التقتية الرقمية الحديثة في التصميم الطباعي لترويج الاعلانات في شبكات التواصل الاجتماعي التهائي
}

\author{
م.م. طيبة محمد شكري جميل

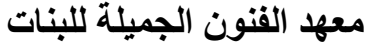

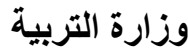 \\ العراق
}

Teba.jamel.m@gmail.com

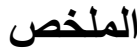

للتقنيات الرقمية المتبعة في الاعمال الطباعبة كبير الأثر في إستحداث بناءات فنبة تصميمية لمعلقات مطبو عة، ونظر الإفتقار تصميمات المطبو عة المستمدة من التأثثرات الفنية السطحية للتقنيات الطباعية، لذا تم التركيز على النواحي الجمالية والتجريبية لكثف النقاب عن التقنيات الطباعية والتأثثرات الفنية لملامسها السطحية مما قد يثري في ترويج الاعلانات في الاعلان المطبوع. وتعتمد التقنية في تناول الجانب الإبتكاري في التصميمات

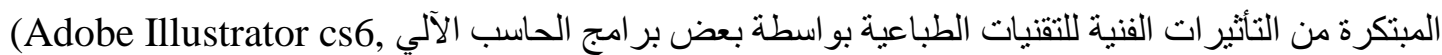
. Adobe photoshop cs6 ) , في وسائل التو اصل الاجنماعي.
\end{abstract}

الكلمات المفتاحية: التقنية الرقمية الحديثة، التصميم الطباعي، ترويج الاعلانات، التو اصل الاجتماعي. 


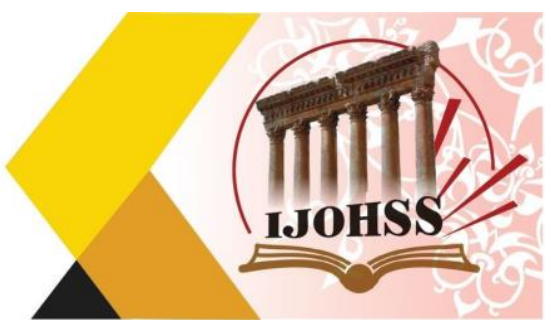

\title{
Recruit the modern digital technology in printing design for promote advertisements in social networks
}

\author{
Assist. Lect. Teba Mohammad Shukry Jameel \\ Institute of Fine Arts - Baghdad \\ Ministry of Education \\ Iraq \\ Teba.jamel.m@gmail.com
}

\begin{abstract}
The digital techniques used in the printing work have a great impact in the development of artistic designs designed for printed posters, and due to the lack of printed designs derived from the surface artistic effects of printing techniques, so the focus was on the aesthetic and experimental aspects to unveil the printing techniques and the artistic effects of their surface touches, which may enrich the advertising promotion In the printed advertisement. The technology is adopted in dealing with the innovative side in the innovative designs of the technical influences of printing technologies by some computer programs (Adobe Illustrator cs6, Adobe Photoshop cs6). These technologies have met with great acceptance and approval among the recipient through interaction on social media.
\end{abstract}

Keywords: Modern digital technology, printing design, Advertising promotion, Social Media. 


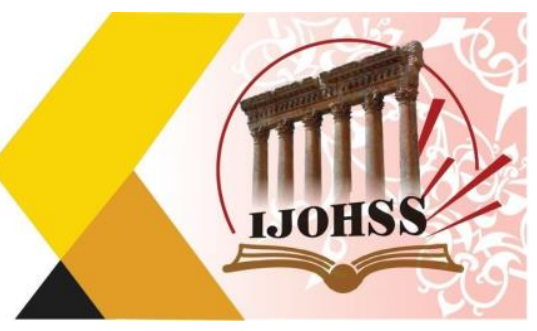

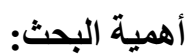

قدمنا في هذا المنجز فرضاً يمكن إستنباط مداخل جديدة للتصميم المطبوع من خلال التأثيرات الفئية الفية السطحية

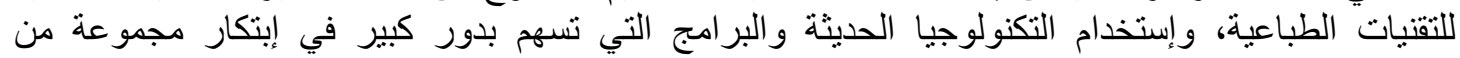

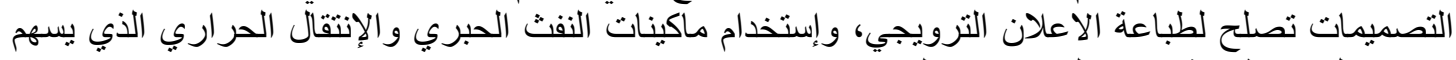
بدور فعال في طباعة بعض التصاعة الاعلان لتريمات التي سيتم تنفيذها.

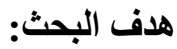

يهدف البحث إلى إثراء مجال التصميم الطباعي من خلال تجميع وتحديد أساليب التقنيات الطباعية والتأثيرات الفنية لملامسها السطحية و إنبساط القيم الجمالية لها.

مشكلة البحث:

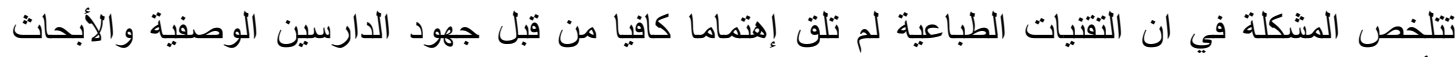

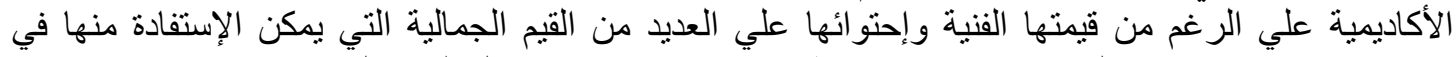

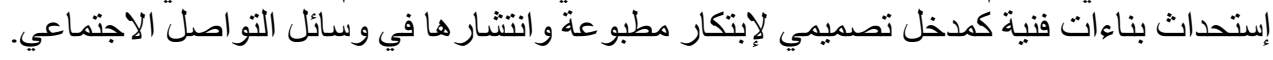

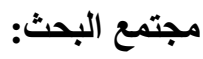

لقد تم اختبار (4) نماذج او تصميم رقمي كعينة لمجتمع البحث تشكل اعلانا ترويجيا طباعيا إرشاديا او منشورا باتباع التقنية الرقمية الالكترونية منها ورفعها في وسائل التو اصل الاجنماعي.

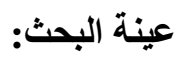

اعتمد الباحث القصدية في اختبار نماذج البحث، وقد بلغ عدد نماذج البحث (4) كتصاميم طباعية رقمية إرشادية

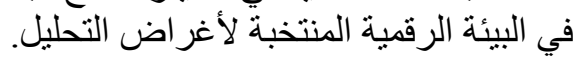

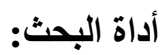
ارتكز تحليل العينة على ما تمخض عنه الإطار النظري من أدبيات البحث لتسهم في تحقيق هدف البحث. حدود البحث: الحد الموضوعي التقنيات الحديثة في التصميم الطباعي في الاعلانات التفاعلية في وسائل التو اصل الاجتماعي.

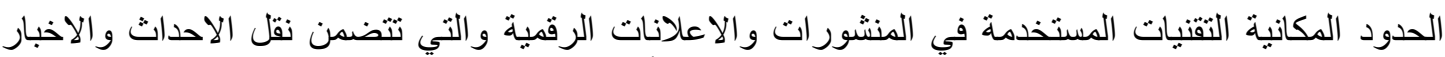
و المعلومات المنشورة في وسائل التو اصيل الاجتماعي وذللك لأعتمادها على التهات التقانات الحديثة في معالجة التصميم و واستعمال عناصر بيئية طبيعية.

$$
\text { تعريف المصطلحات: }
$$

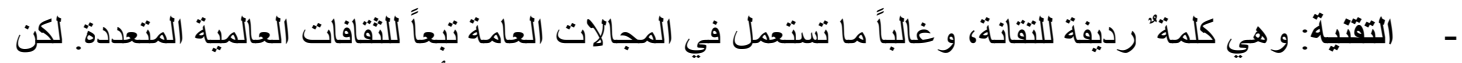

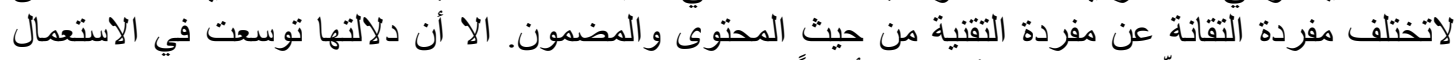

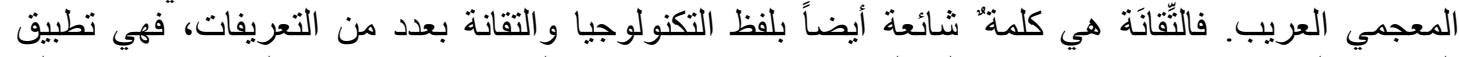

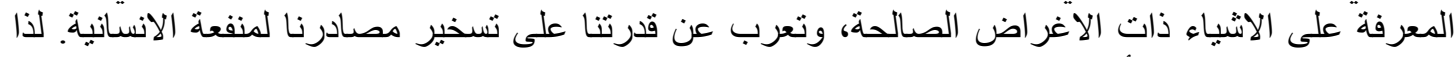

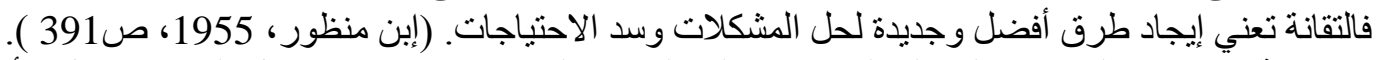

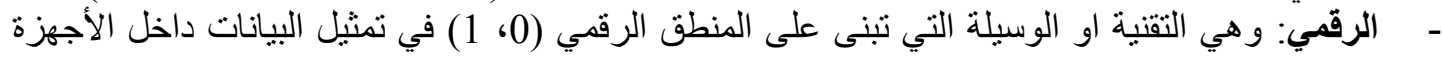

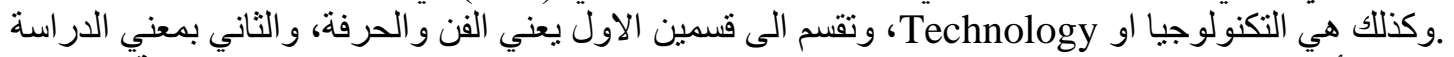

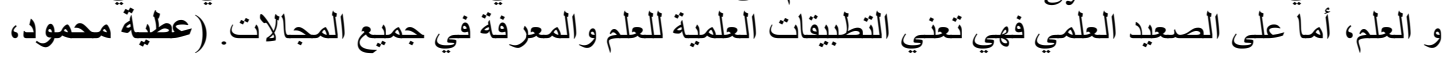




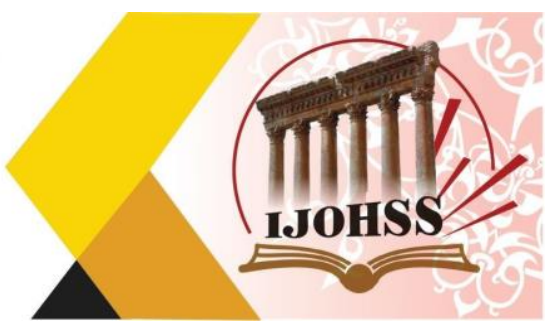

321). وفي الاصطلاح فهي تدل على التكنولوجيا والطرق التي يستخدمها الناس في اختر اعاتهم واكتشافاتهم لتلبية حاجاتهم و إنشباع رغباتهرح.

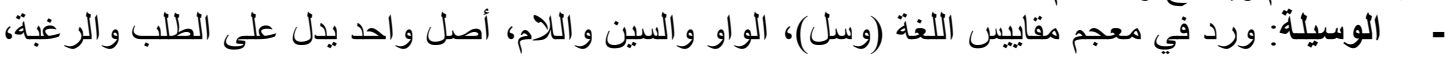

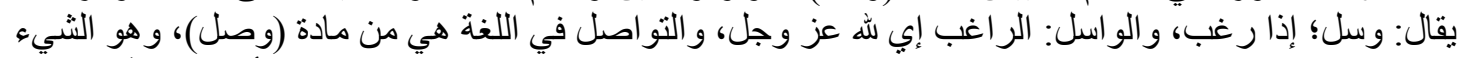

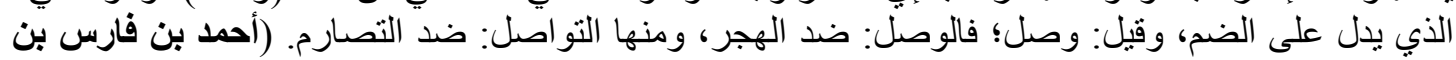

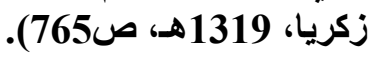

التعريف الاجرائي:

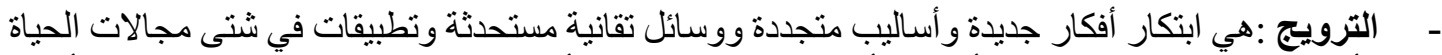

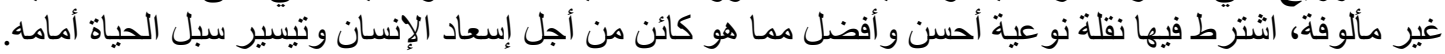

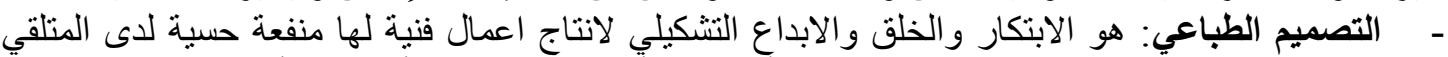

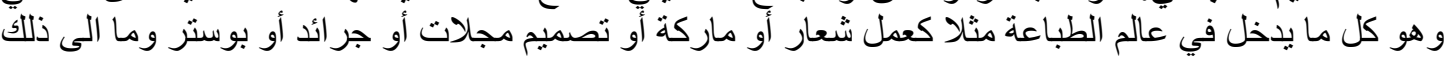

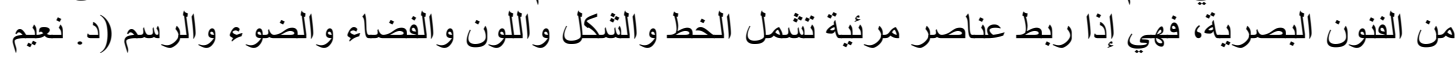

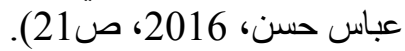

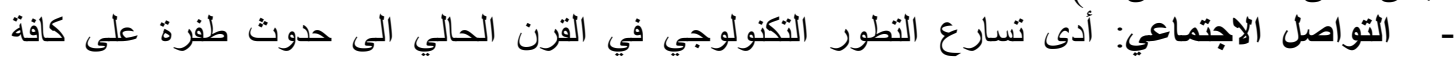

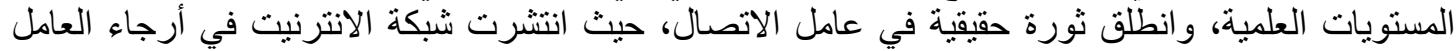

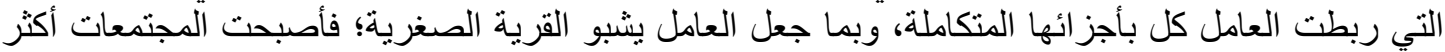

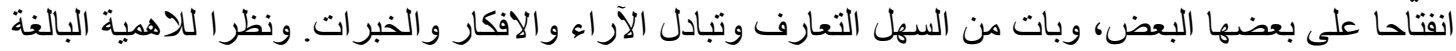

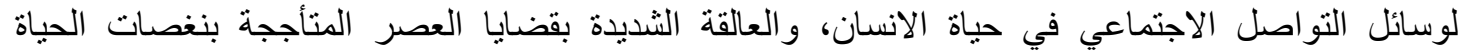

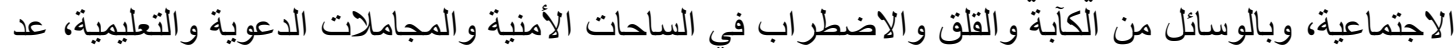

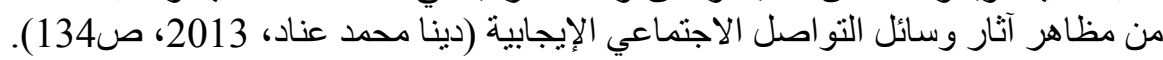

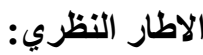

\section{1أروى المستقبلية في فلسفة الترويج}

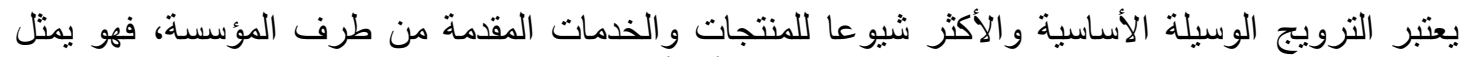

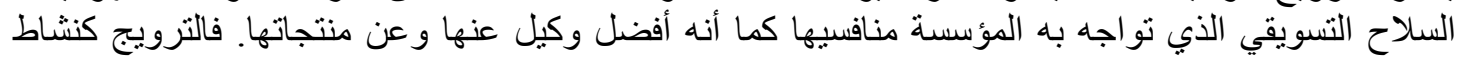

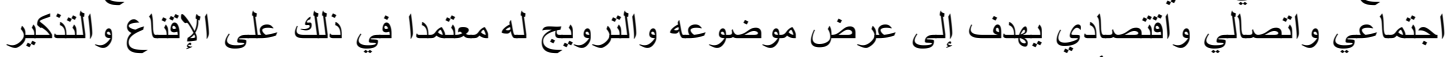

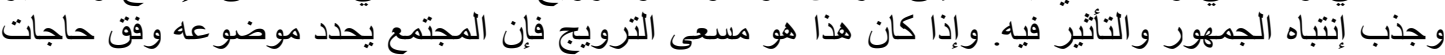

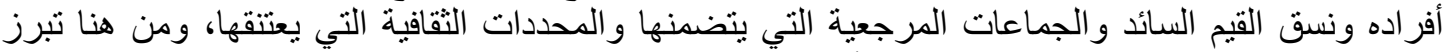

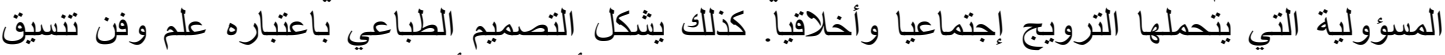

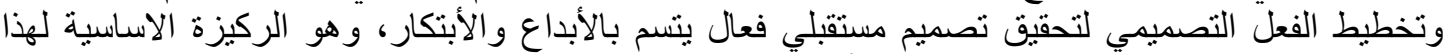

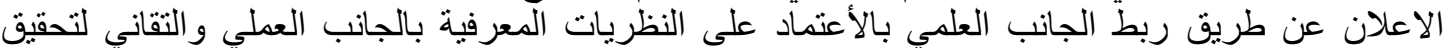
اهداف مستقبلية وحلول للمشاكل.

تعتمد استر اتيجية التصميم الطباعي على مجمو عة من القوى الفنية وماتحمله من خو اص وسمات التهات تحاول أن نترك

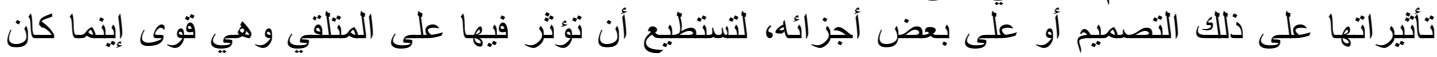

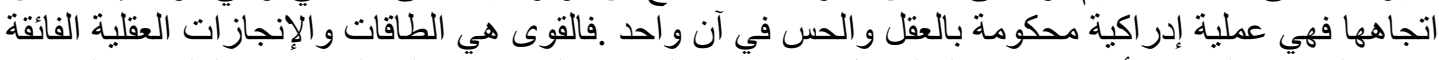

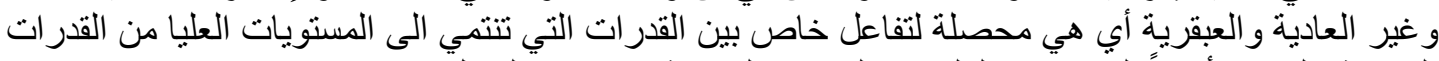
الخاصة بالذكاء و أيضاً المستويات أيتي العليا من القدر ات الخاصة بالابداع والخيال.

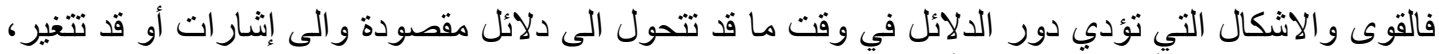

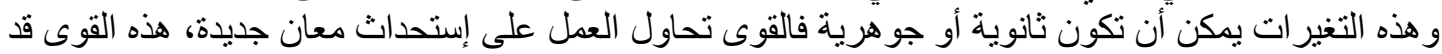

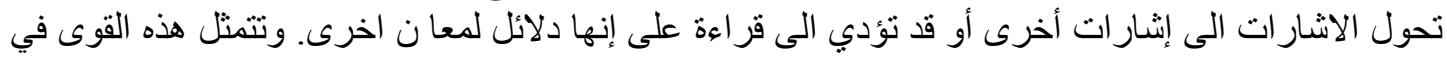




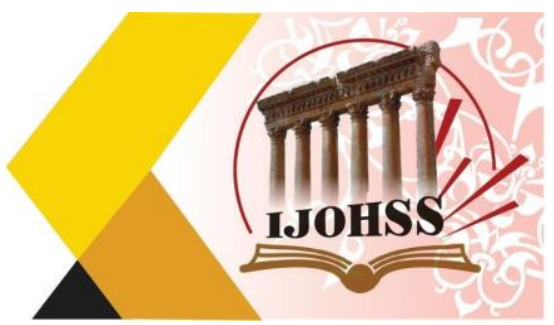

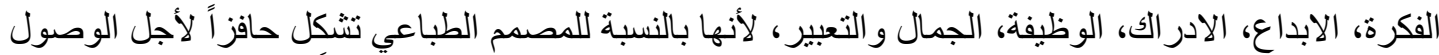

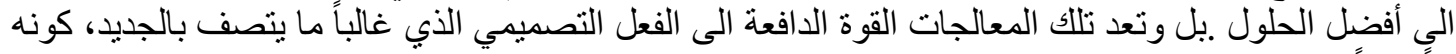

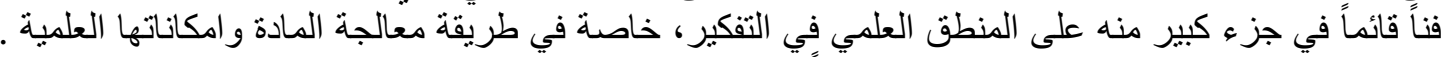

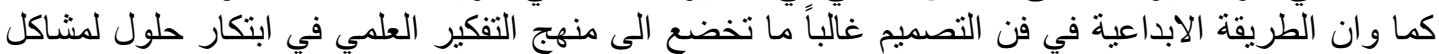

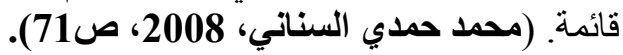

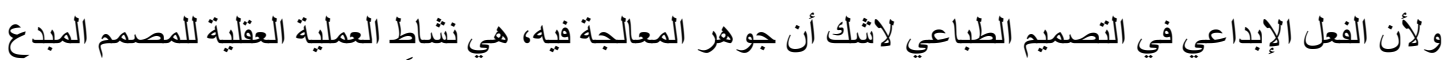

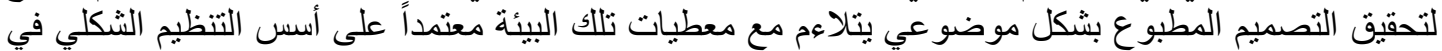

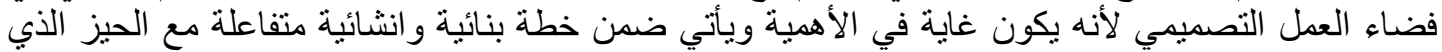

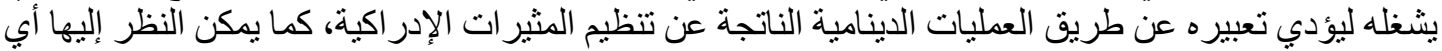

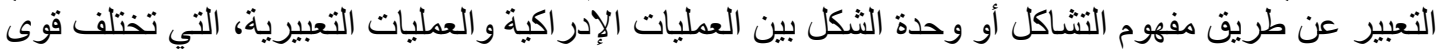

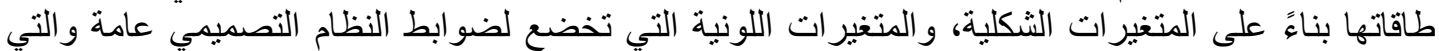

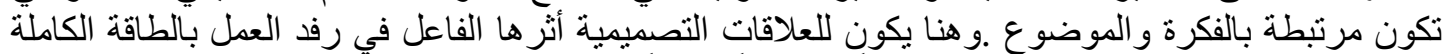

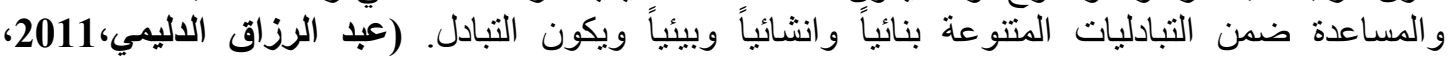

ص234).

\section{2. مفهوم التصميم الطباعي واستخدام التقتية الرقمية:}

ويقع فن التصميم الطباعي ضمن الحاجات الاكثر رسوخا متعددة من وسائل الاتصال و أنه نوع من الاتصال الإليال

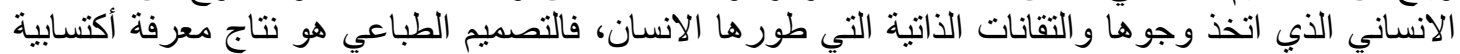

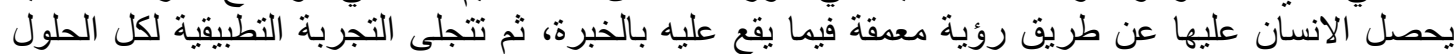

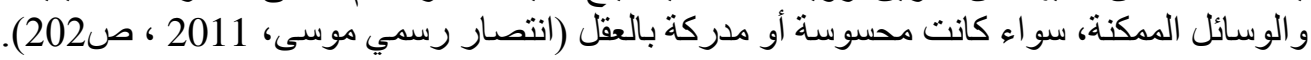

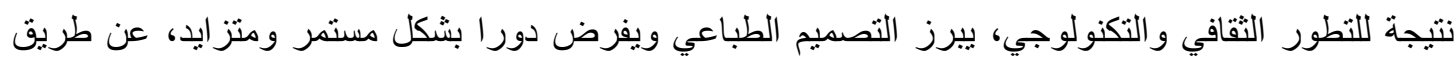

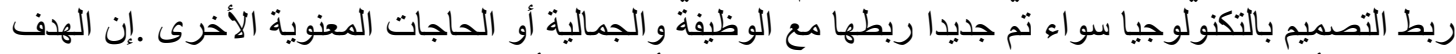

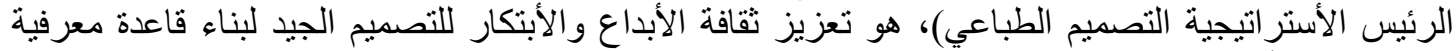
تحقق البنى الأرتكازية، عن طريق رؤية خطة العمل التصميمي وتحديد نقاط التابل القوة في التصميم الفريد لبناء نهاء

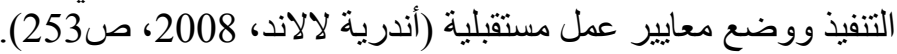

ويعد التصميم الطباعي ذو أهمية كبيرة للمصمم، لما لها من أثر بالغ في تكوين التصميم الملائم و الجذاب للمتلقي.

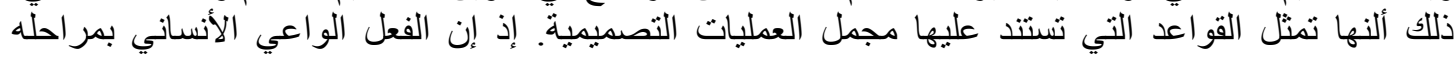

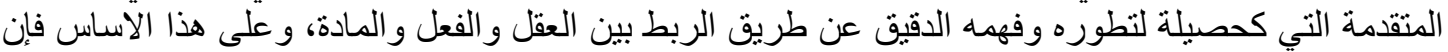

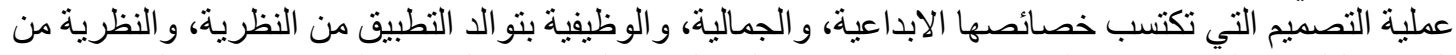

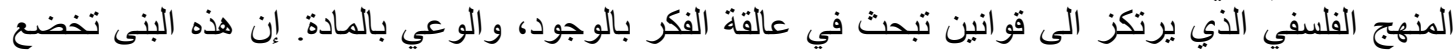

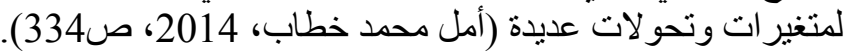

اذ يعد التصميم الطباعي نتاج معرفة أكتسابية يحصل الإنسان عليها عن طريق رؤية معدقة فيما يقع عليه

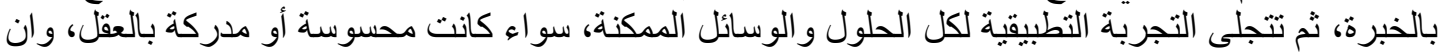

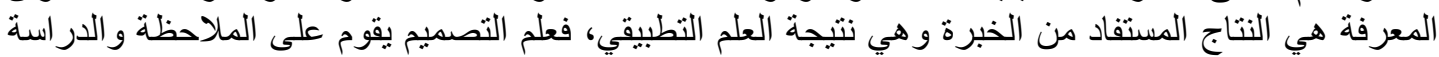

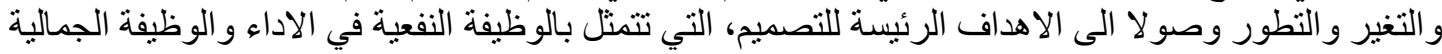
التي توضع في الاعتبار الجمالي للتصميم (باسم قاسم الغبان، 2014، ص لانس 135). 3. أساليب الترويج في مواقع التواصل الاجتماعي: إن وسائل التو اصل الاجتماعي تتسم بخصائص ومميزات قيمة ذبلها تو اكب التطور ومنها: 


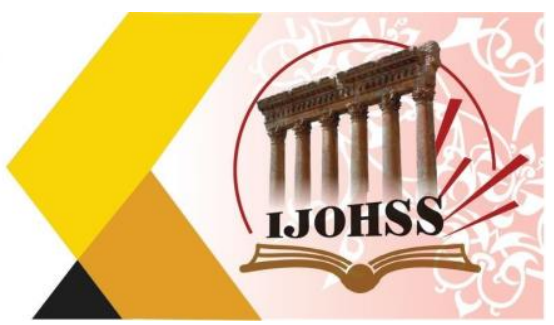

ـ الفاعلية Interactivity : وهي خصيصة تتيح للمتلقي أن يناقش مقابل في قضية ما، وأن يعلق عليها عن طريق الدردشة أو المشاركة في المنتديات وما الى ذللك من الوسائل و الدو افع إن في في

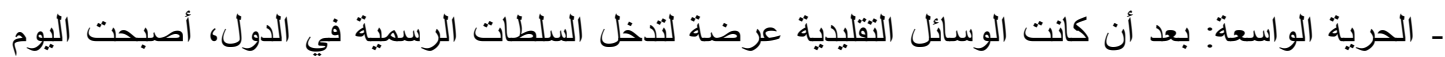
مفتوحة للجميع و على الجميع، و إن ذلك يعد نفعا في حين فقد تجلب الثر في حين آخر.

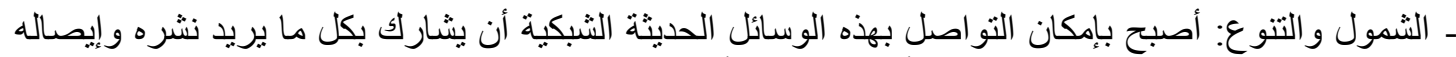

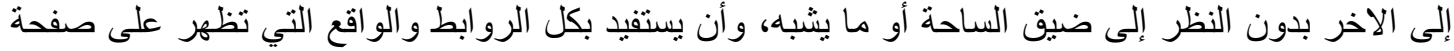

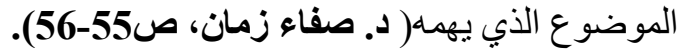

ـ التو افر و التحديث المستمر: يمكن لكل مستخدم أن يبقى على معرفة مستمرة بالو اقع في مجيع أضلاء العامل بدون انقطاع و الانتظار . النقان

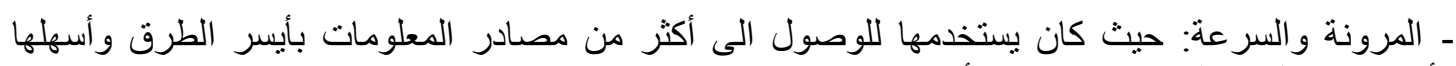

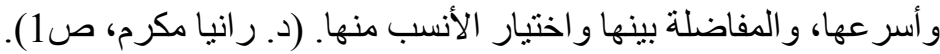

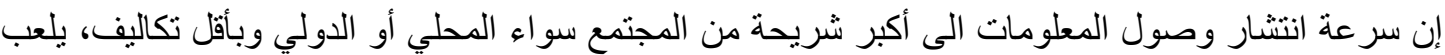

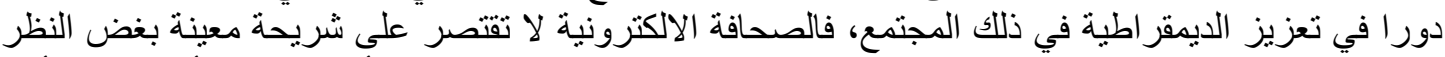

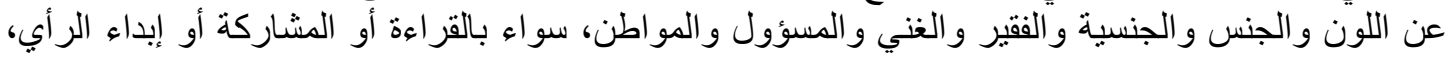

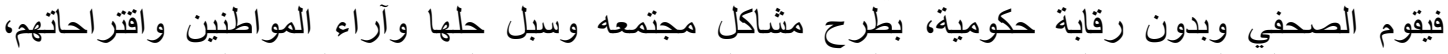

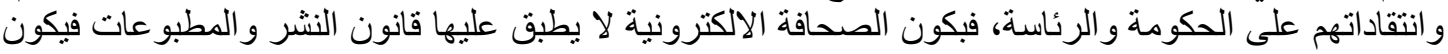

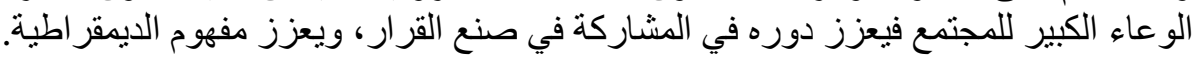

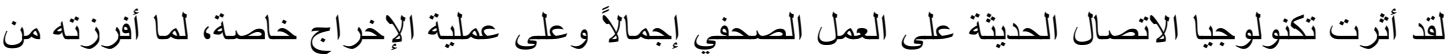

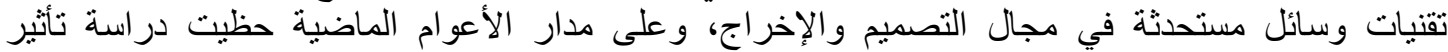

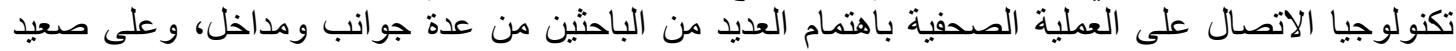

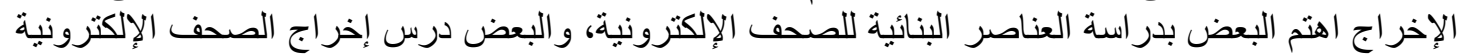

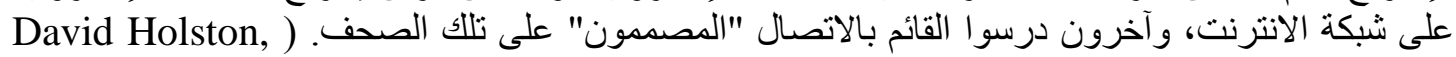
.(2009, p. 306.

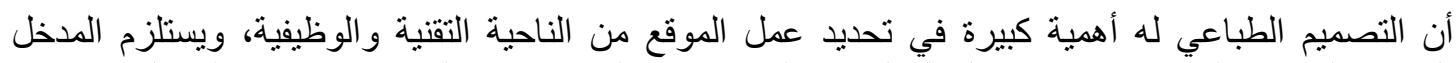

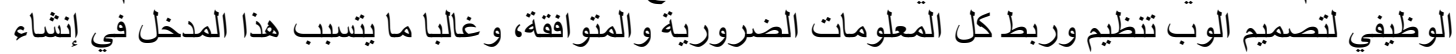

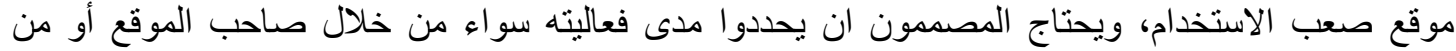

منظور المستخدمين.

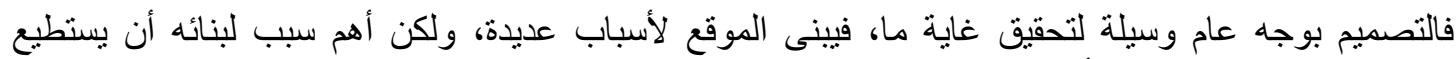

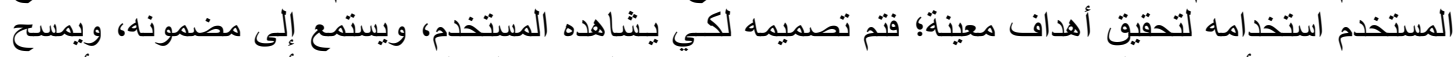

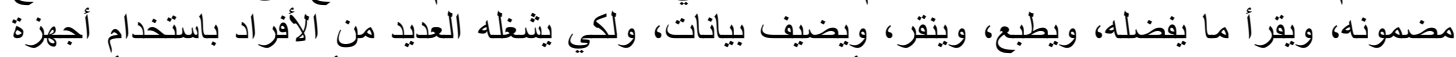

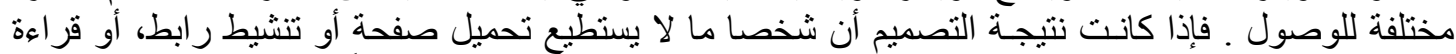

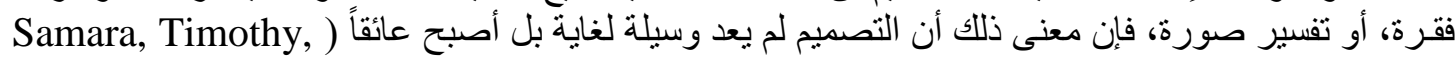
.(2017, p.p. 194.

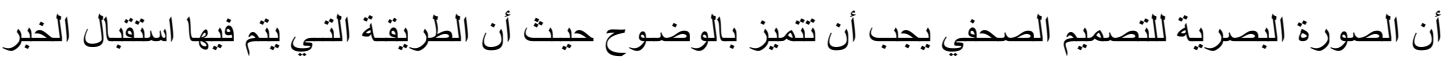

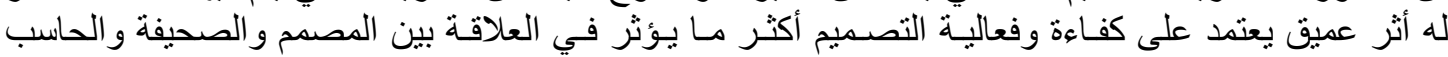

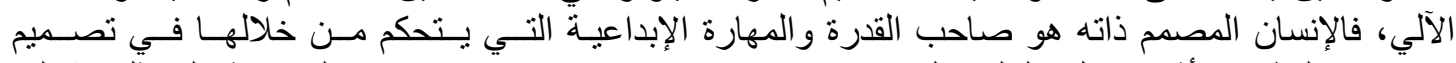

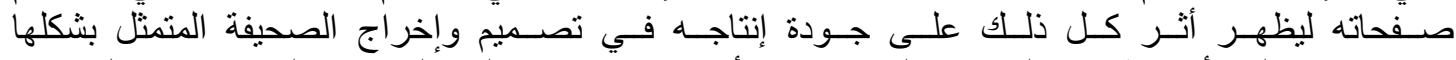

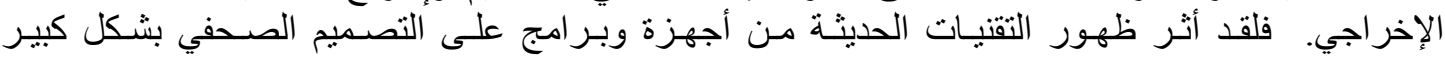




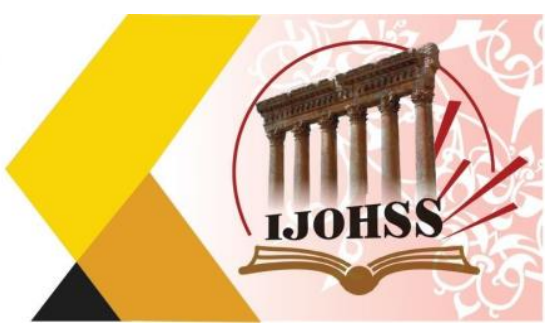

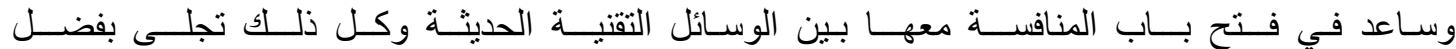

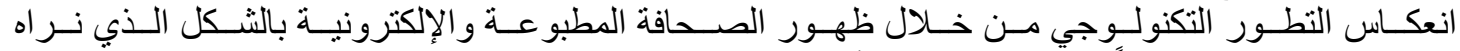

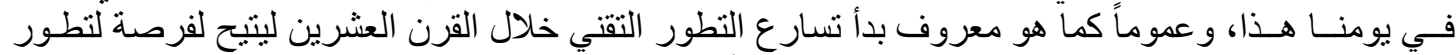

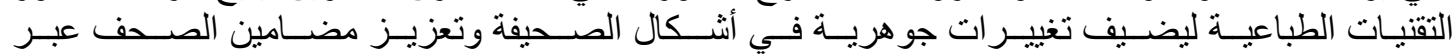

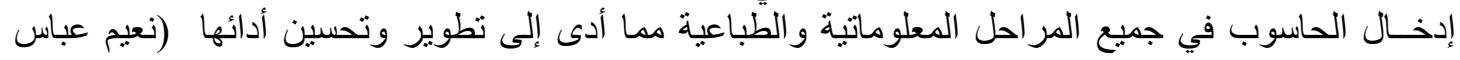

حسن، 2016، صنون (199).

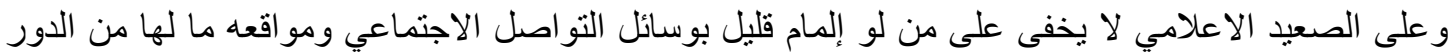

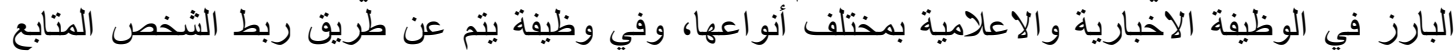

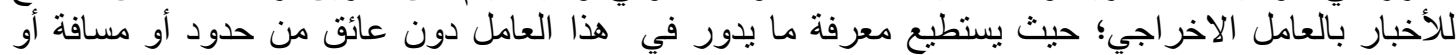

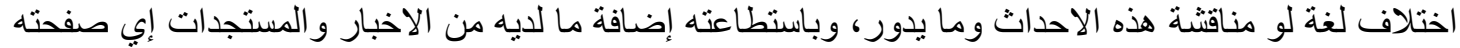

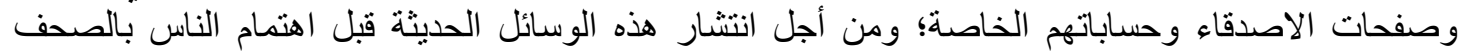

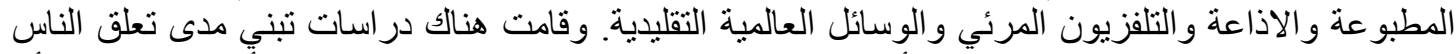

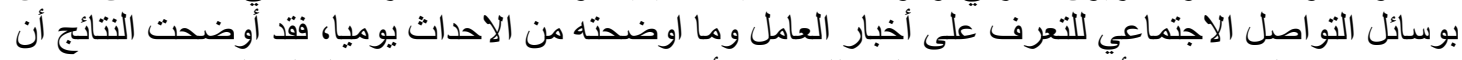

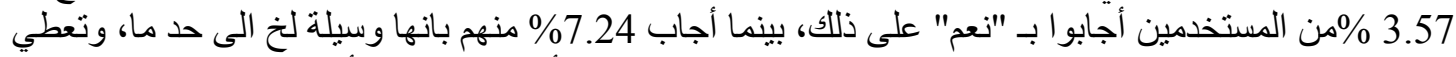

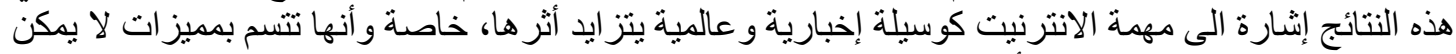

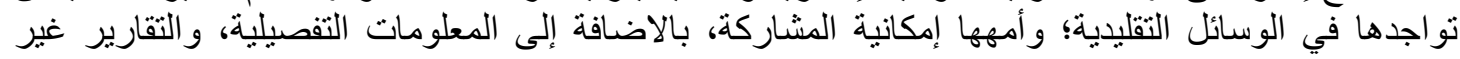

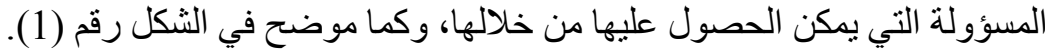

أن عدم تزامنية البث تساهم في ارتفاع نسبة المستخدمين في مجال الثقافة العامة والتعليم. (الاثار الاجتماعية

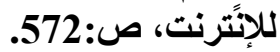

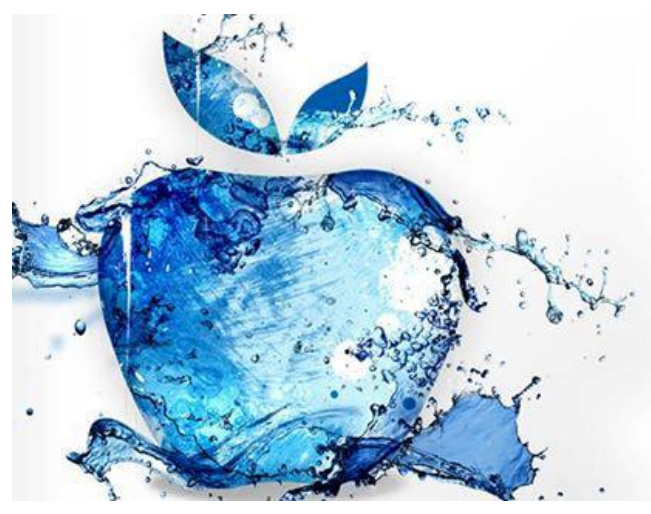

الثكل رقم (1) تزامنية الحدث من خلال التصميم الطباعي كنموذج للترويج عن الخدمات والمنتجات عبر مواقع التواصل الأُجتماعي التئي

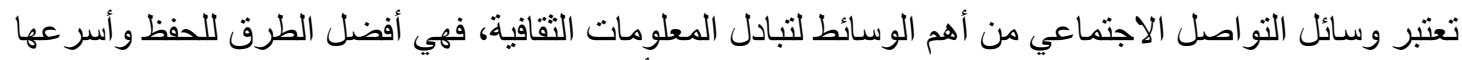

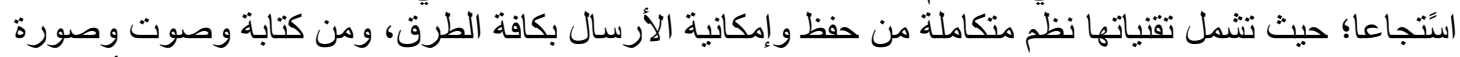

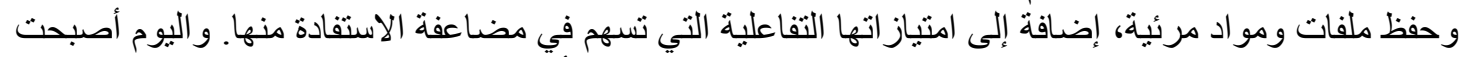

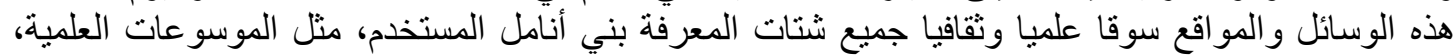

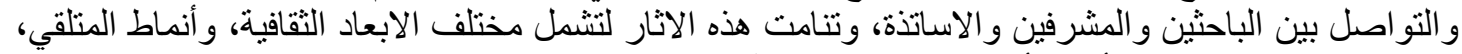

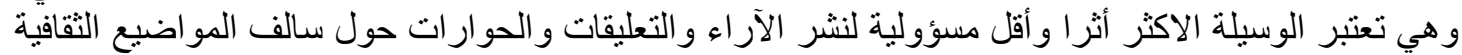

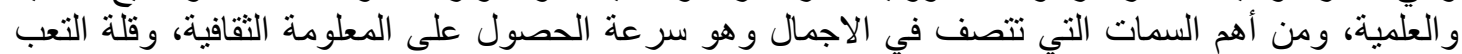

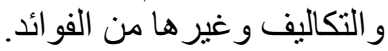




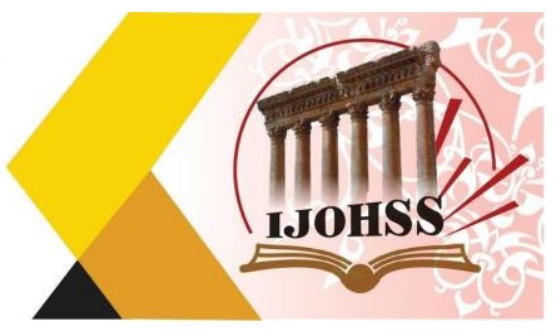

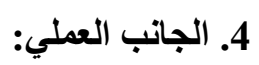

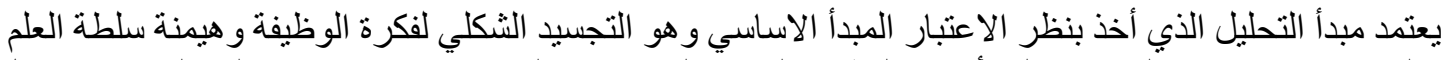

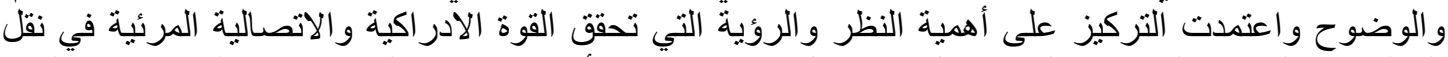

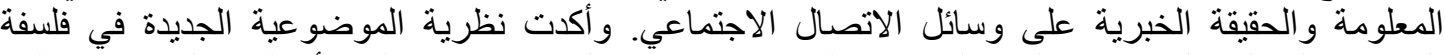

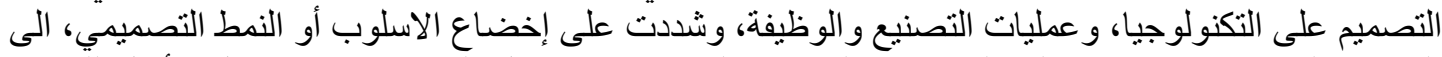

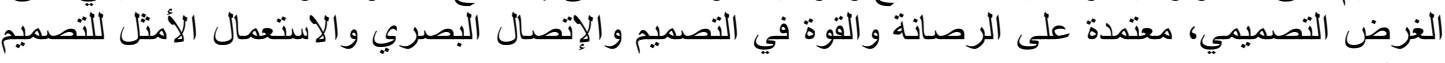
و عناصره.
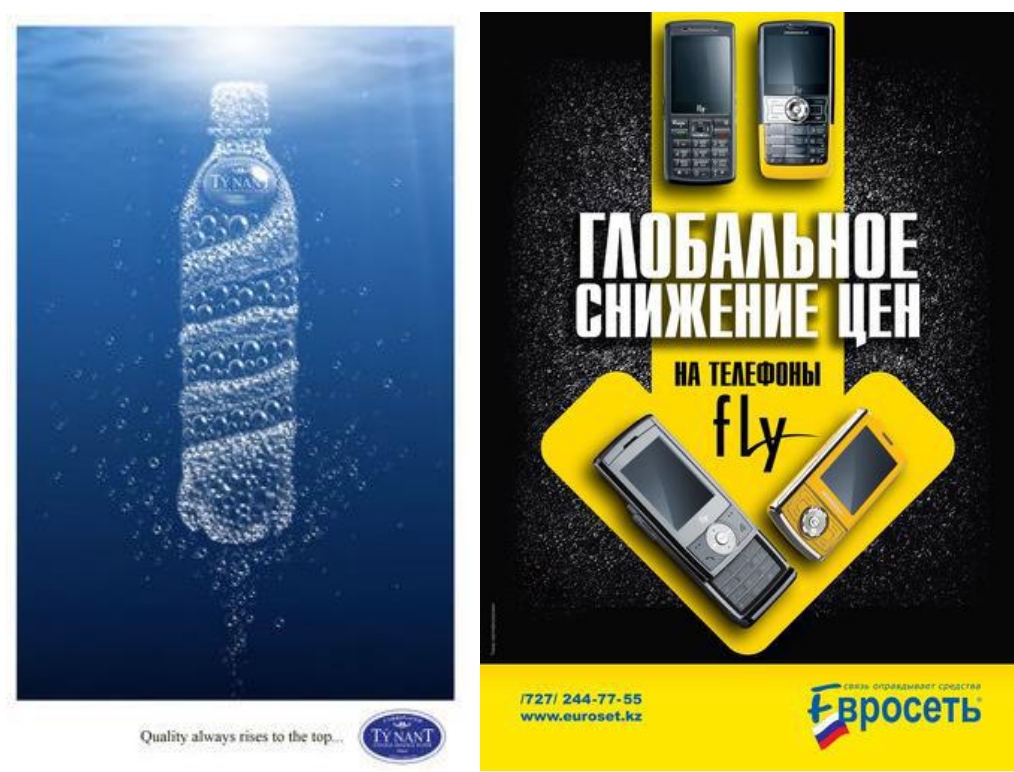

شكل رقم (2): اسلوب المصمم الطباعي في ابراز دور التفاعل واظهار الاعلان الترويجي بالصورة والالوان والثكل.

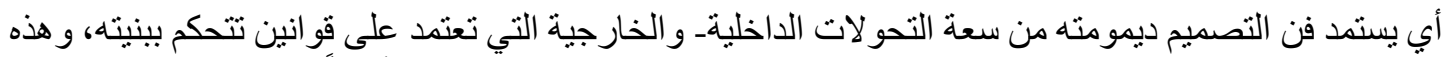

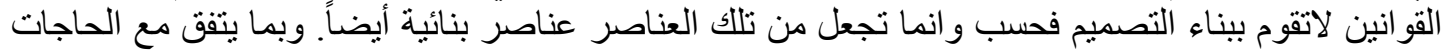

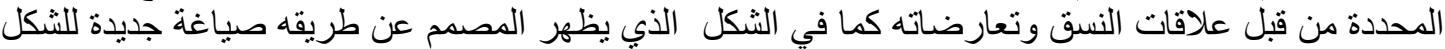

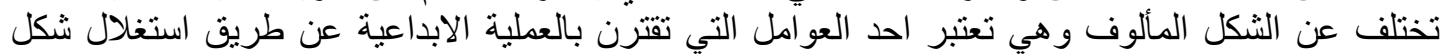

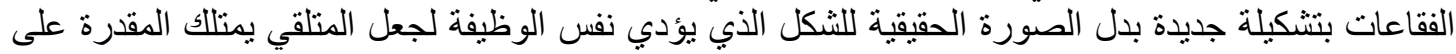

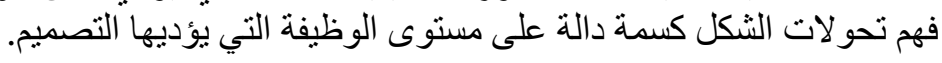

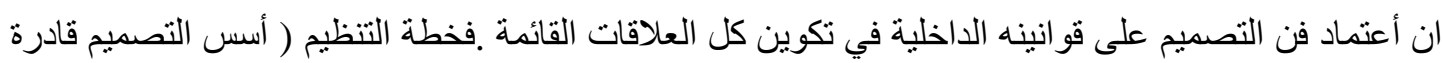

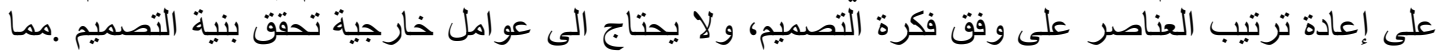

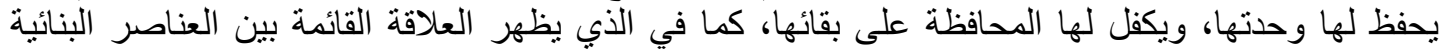
و الاسس التنظيمية للوصول الى نظام مغلق لا يدع لأي مؤثر خارجي. 

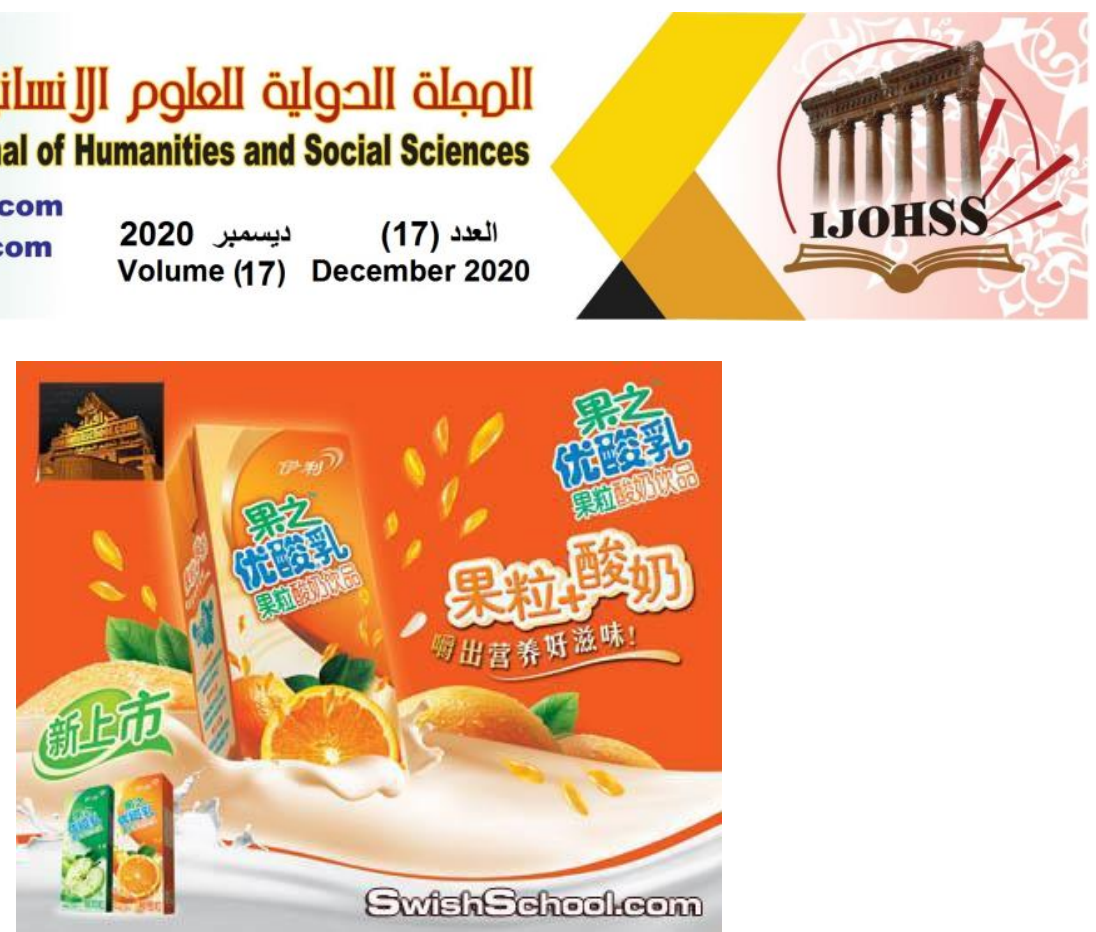

الثكل رقم (2): شعار لاحد الملصقات الاعلانية والترويج في صفحات وسائل التواصل الاجتماعي

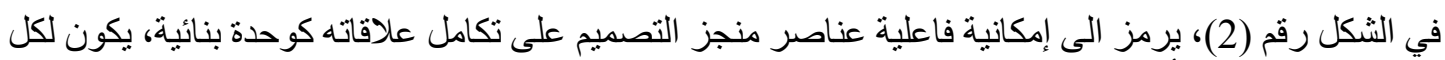

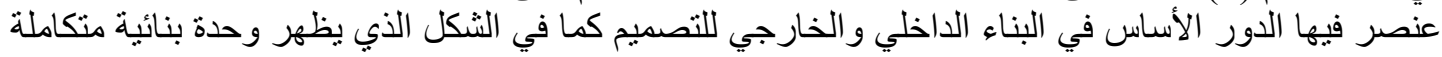

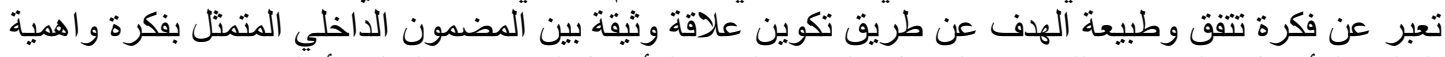

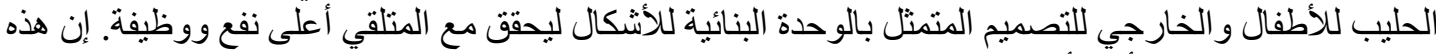

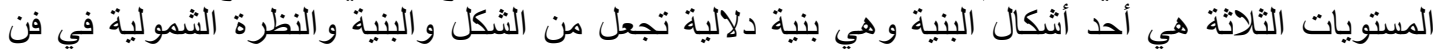

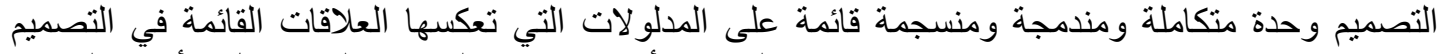

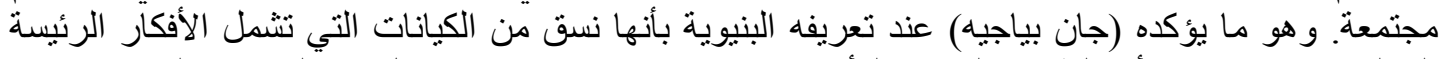

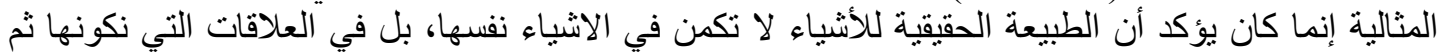
ندركها بين هذه الأشياء.

إن بناء الثكل التصميمي الجديد يتم بقصدية لكي يؤدي الى نسق مثير سيكولوجياً وجمالياً فضلاً عن الديناميكية

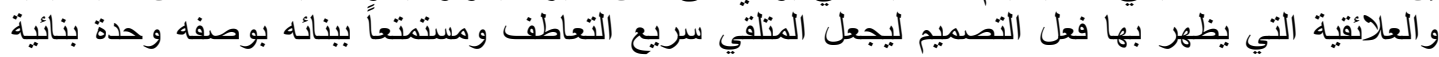
متكاملة.

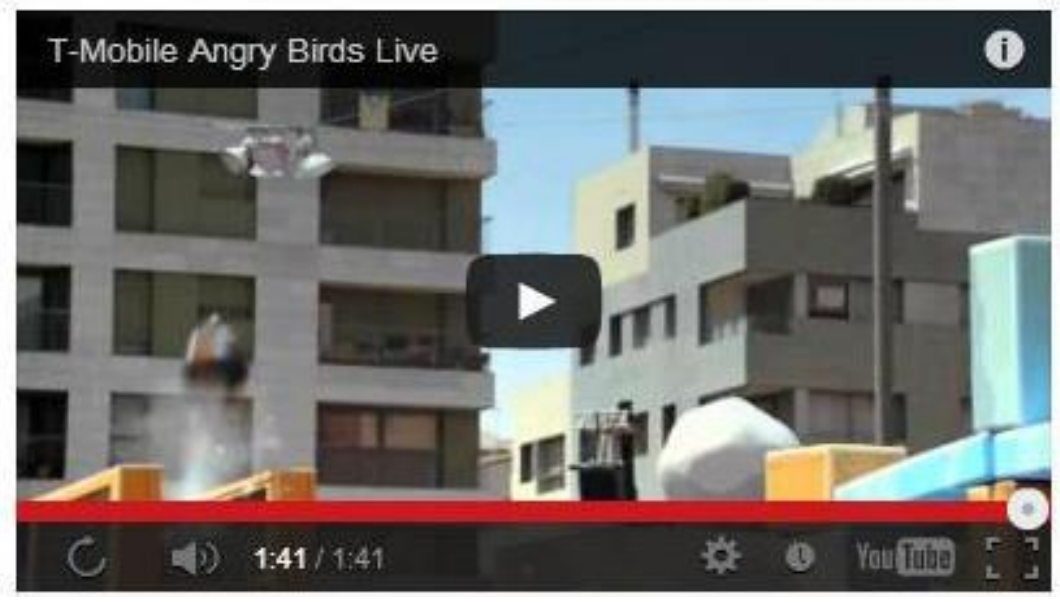

الثكل رقم (3): نموذج لاعلان تفاعلي على احدى صفحات التواصل الاجتماعي (تويتر) 


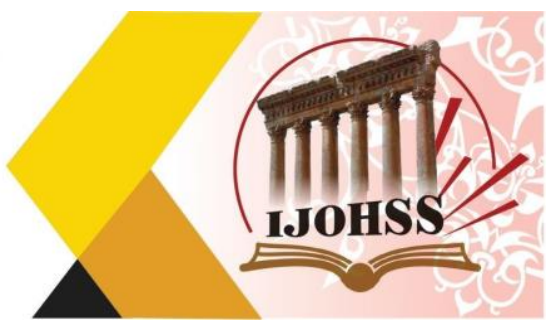

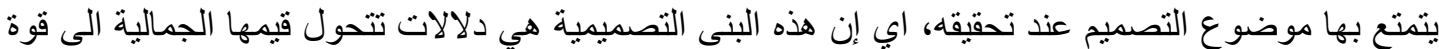

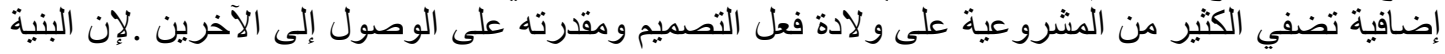

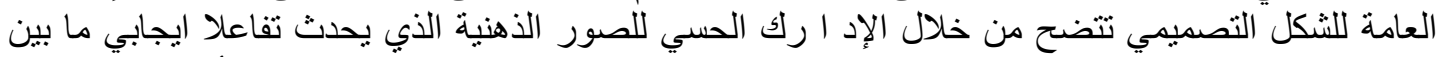

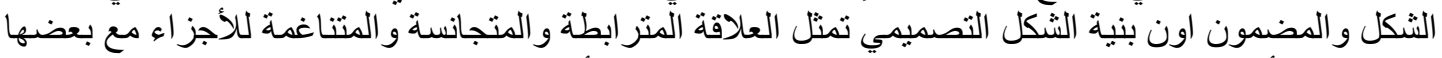

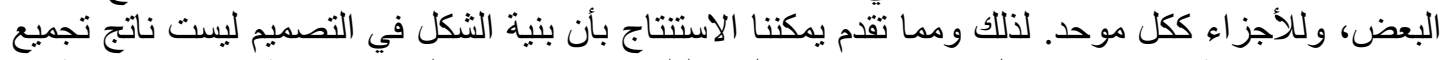

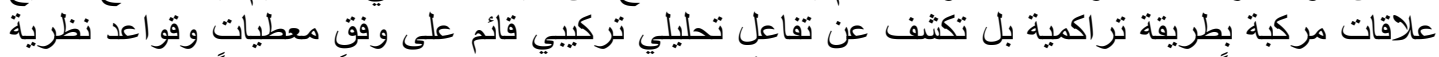

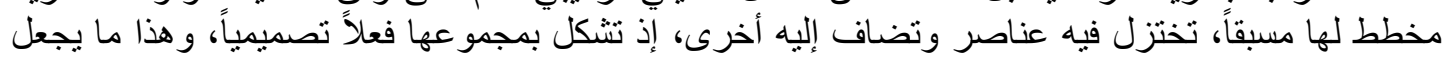

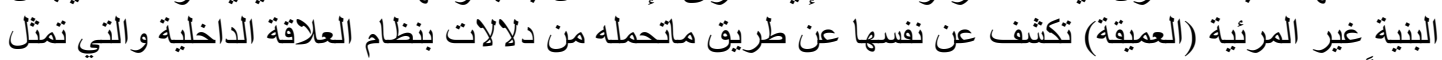

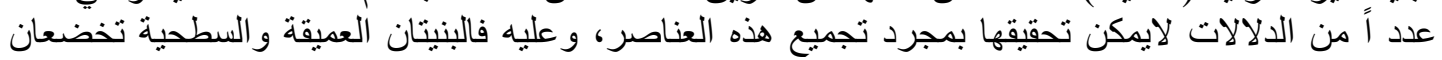

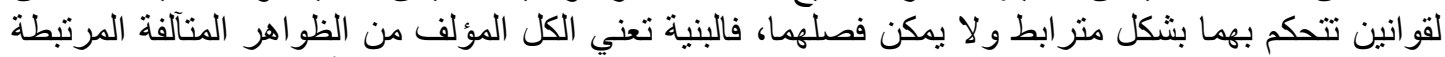

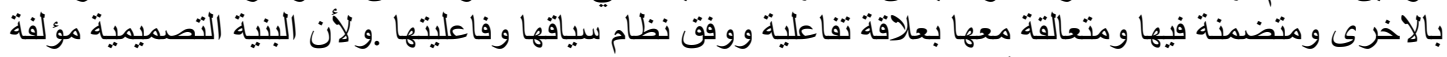

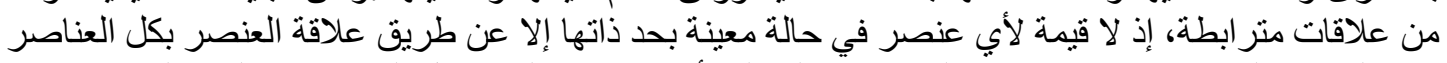

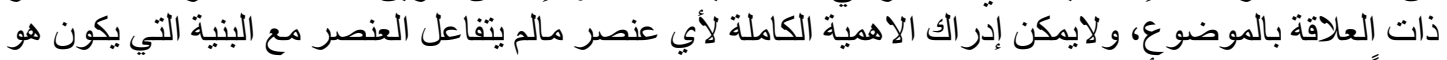

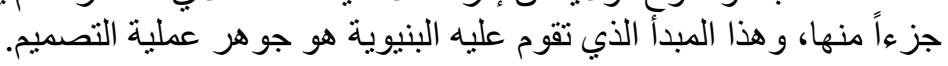

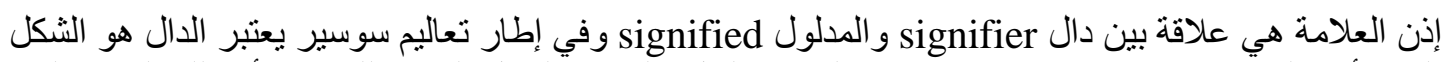

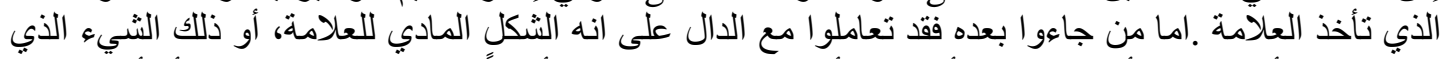

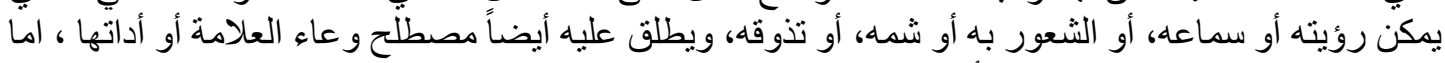

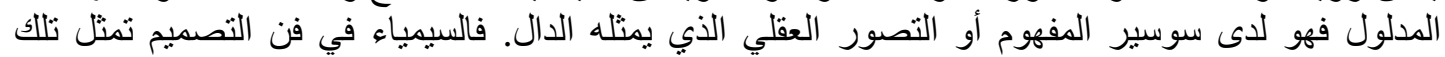

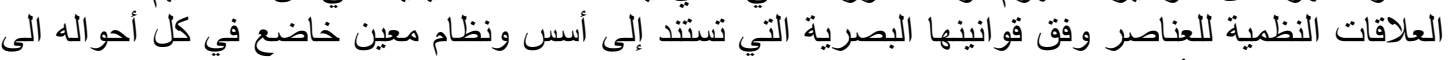

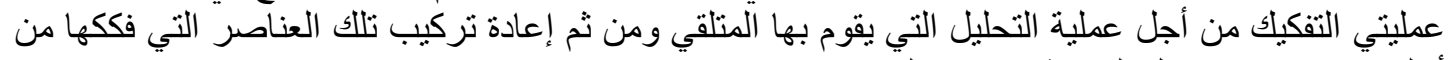

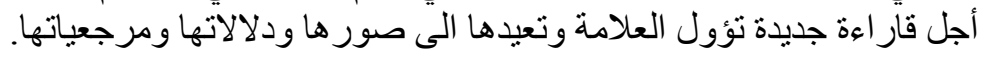

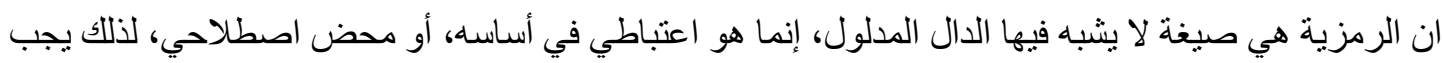

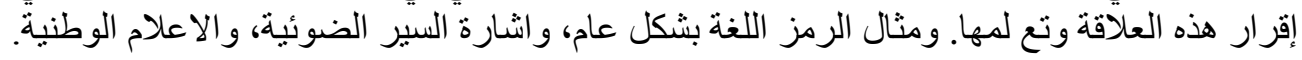

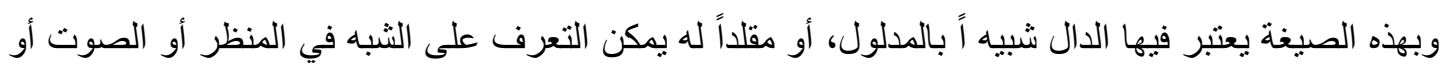

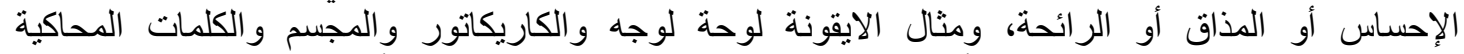

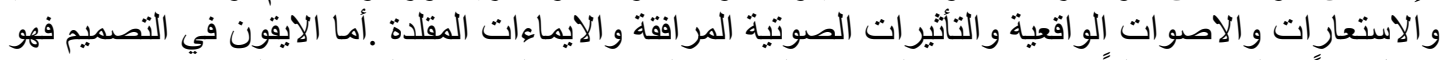

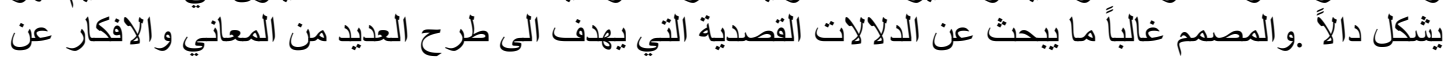



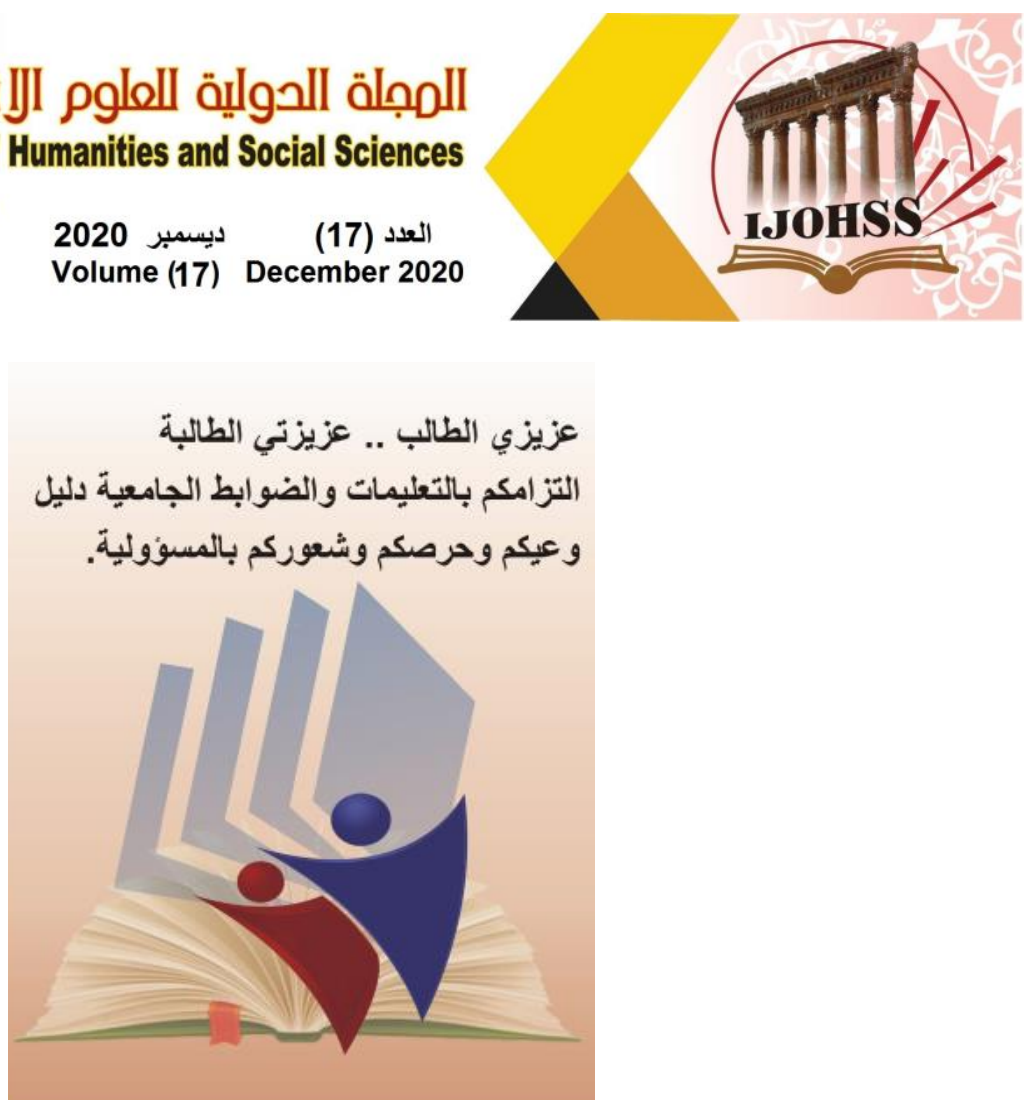

الثكل رقم (4) : الاليل الارشادي للطلبة كنموذج للعملية الترويجية على اسس تعليمية في احدى صفحات

وسائل التواصل الاجتماعي (Facebook).

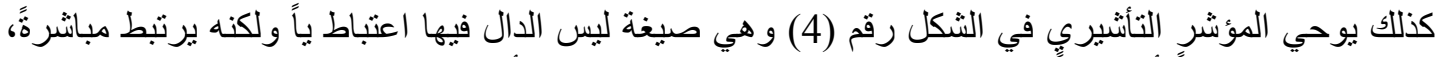

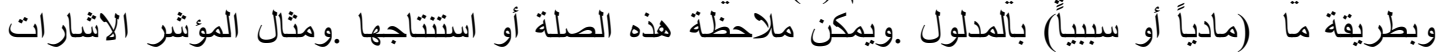

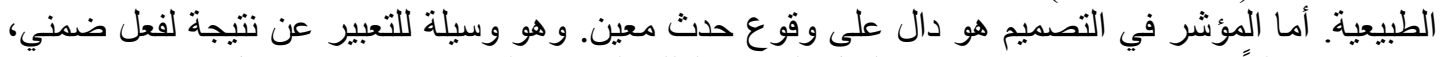

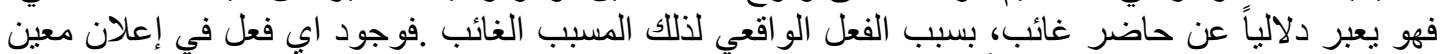
دليل على تضمين هذا الإعلان حدثاً أدى الى ذلى ذلك الفعل.

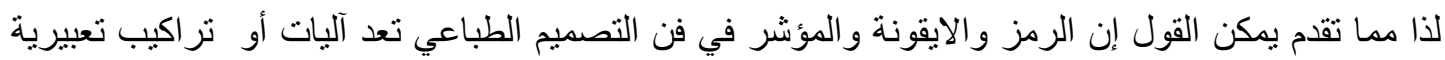

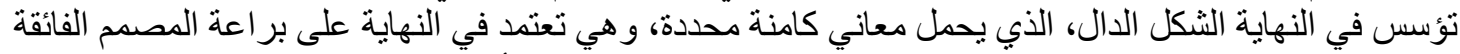

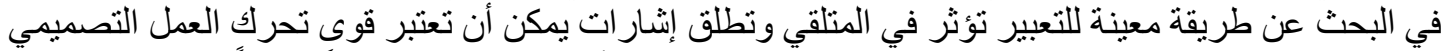

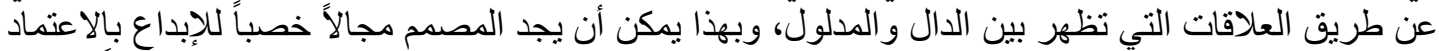

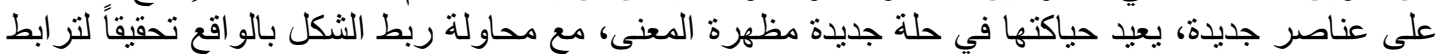

$$
\text { دلالي وموضوعي. }
$$

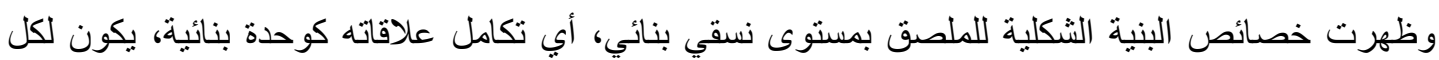

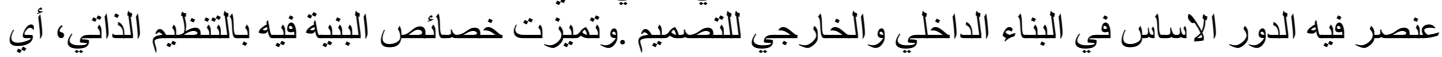

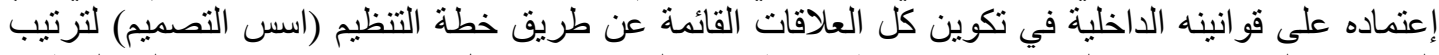

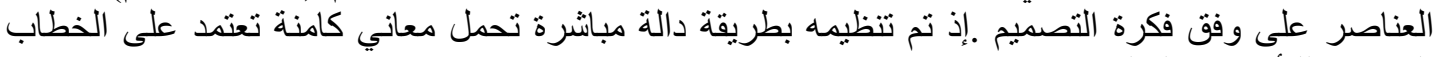
البصري للتأثير في المتلقي.

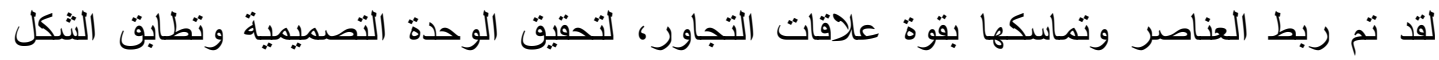

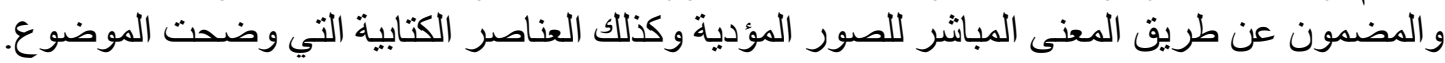

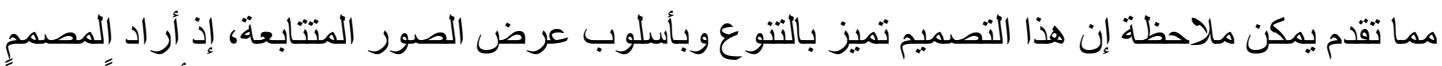

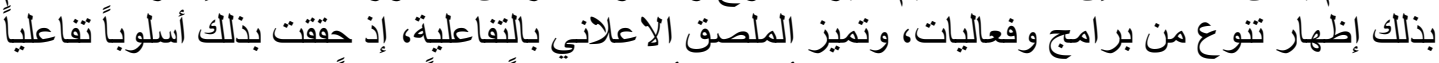

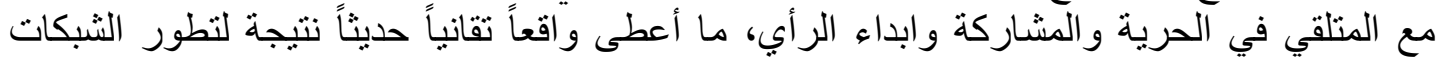
الاتصالية والمعلومات الالكترونية، لتجسيد ثورة الاتصال عن طريق إنداء إنداج المعلومات ووسائل 


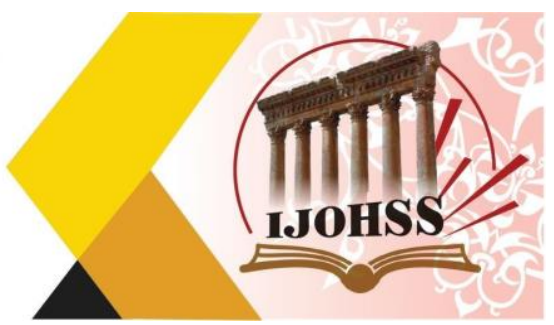

الاتصال وتعدد أساليبها أو بمعنى آخر المزج بين أكثر من تكنولوجيا إتصالية تمتلكها أكثر من وسيلة

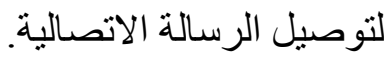

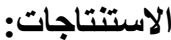

من خلال التحليل توصلت الباحثة الى النتائج الاتية:

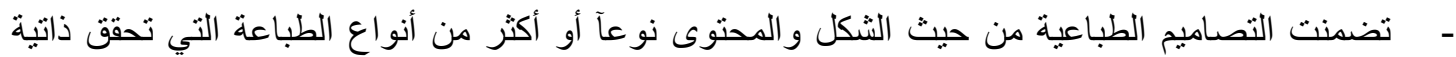

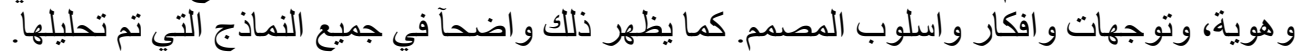

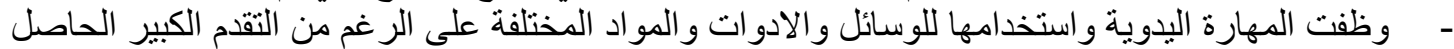
في التقانة المعاصرة في مجال التصميم و الطباعة. كما في النماذج المبادئ المبينة.

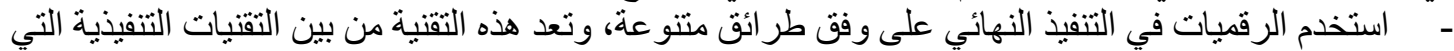

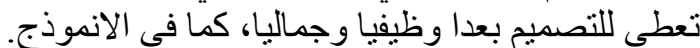
- ـلمهارة باستخدام التقنيات الرقمية لها دور فاعل في اضفاء لمسة فنية تبرز الجانب الجمالي للمنجز ـ الطباعي. أنظة الحواسيب التصميمية وسائل منكاملة لمساعدة المصممين في إلانجاز الطباعي ونوسيع افاقهم وخبر اتهم وخبراتهج

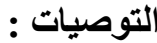
- التأكيد على دور المهارة اليدوية في أنجاز التصاميم الطباعية من خلال الاهتمام بالمفردات الدراسية في

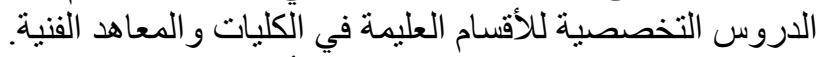

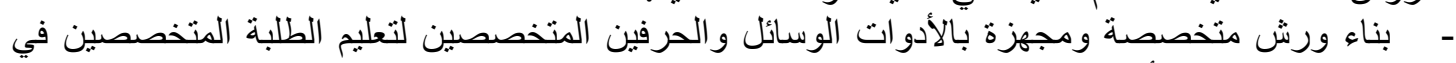

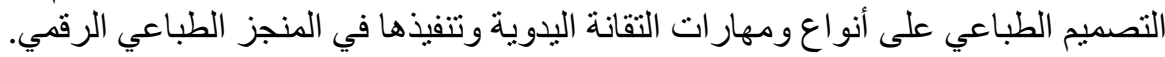

المصادر

1. أبن منظور، لسان العرب، تقديم :الثيخ عبد الله العلايلي، أعداد وتصنيف :يوسف الخياط، دار لسان الحق،

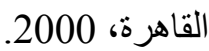
2.

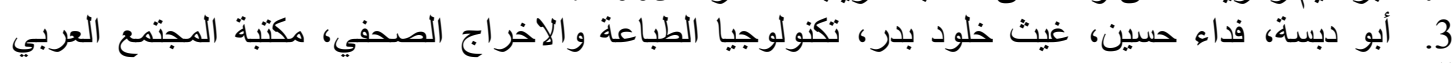

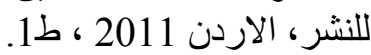

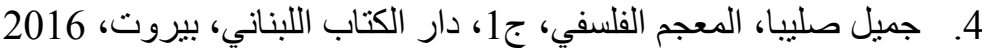
5. خليل ابراهيم، المضامين الفكرية وعناصر التصميم الفني الملصقات في العراق، رسالة ماجستير غير

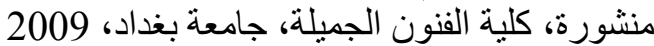

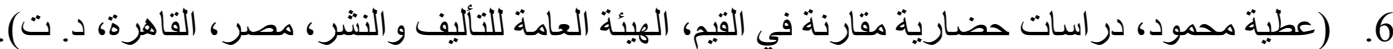

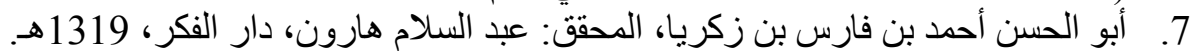

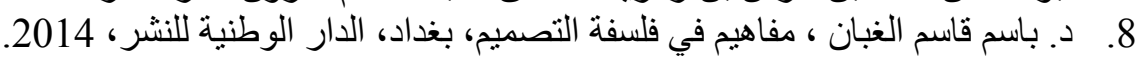

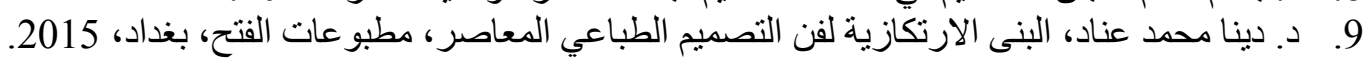

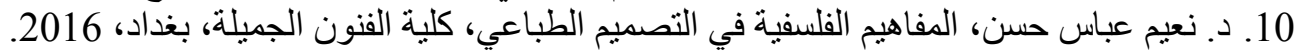

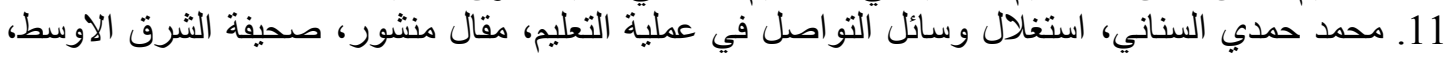




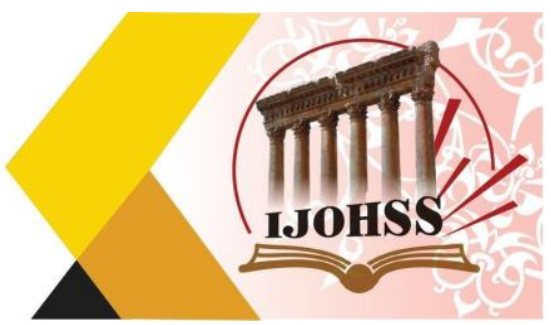

12. أمل محمد خطاب، تكنولوجيا الاتصال الحديثة ودورها في تطوير الأداء الصحفي، دار العالم العربي،

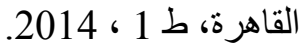

13. انتصار رسمي موسى، خليل ابر اهيم الواسطي، التصميم الرقمي وتقنية الاتصالات الحديثة، ط 1 ، دار

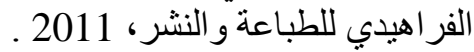

14. د. رانيا مكرم، أثثر مو اقع التو اصل الاجتماعي في تنمية المسؤولية الاجتماعية لدى الثباب، المركز الاقليمي

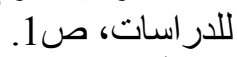

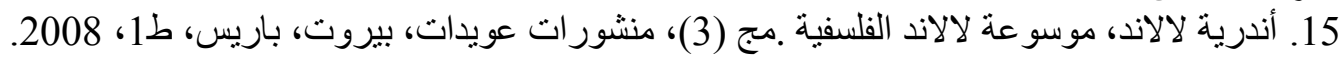

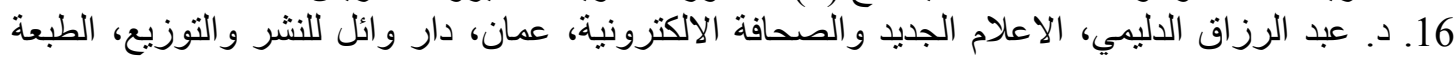

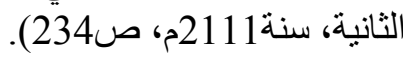

17. د. صفاء زمان، العالم الجديد وشبكات التواصل الاجتماعي، مقال منشور، موقع جمعية المهندسين

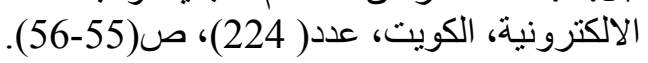

18. David Holston, The Strategic Designer, Manufactured in the United States of America. Copyright @ 2009, First edition.

19. Samara, Timothy, Publication Design Workbook, First published in the United States of America by Rockport publishers, 2017. 